\title{
"Olhares cegos": transformando fotografias em sons - a importância da audiodescrição no acesso à informação por usuários com deficiência visual
}

\author{
"Blind glances": turning photographs into sounds - the Importance of audio description in \\ accessing information for visually impaired users
}



\section{Resumo}

O estudo aborda a temática da acessibilidade, em que por meio da revisão de literatura elucidou os desafios do arquivista na inclusão informacional de usuários com deficiência visual, através do método da audiodescrição como fonte de acessibilidade para estes. Foi utilizado o documento fotográfico com o objetivo de evidenciar a importância da audiodescrição no acesso à informação. As fotografias utilizadas são de exposição do Museu da Imagem e Som do Amazonas (MISAM), onde foram usadas cinco fotografias do fundo documental custodiado pela instituição. Os procedimentos metodológicos utilizados foram de natureza aplicada, pois faz uso da audiodescrição como método para descrever as fotografias do acervo do cineasta Silvino Santos, como também se empregou a pesquisa bibliográfica e documental, sendo este estudo caracterizado do ponto de vista descritivo. Os resultados foram analisados qualitativamente e discutidos com base na fundamentação teórica e a partir desses é proposto que o método de descrição de fotografias de Miriam Manini (2013) pode viabilizar o processo de realização da audiodescrição, garantido assim o direito de acesso e inclusão informacional aos portadores de deficiência visual.

\section{Palavras-chave}

Acessibilidade. Deficiente Visual. Descrição Fotográfica. Audiodescrição de Fotografias. Inclusão Informacional.

\section{Abstract}

This study deals with accessibility through literature review elucidating the archivist's challenges in informational inclusion of visually impairment people, through audio description method as a source of accessibility for them. The photographic document was used to highlight the importance of audio description in access to information. The photographs used are from the archives of the Museu da Imagem e do Som do Amazonas (MISAM). It was used five photographs from the documentary fund 
of the institution. The methodological procedures were from an applied nature, since we used audio description as a method to describe the photographs of the film director Silvino Santos, as well as bibliographical and documentary research. Thus, this study is characterized as descriptive. The results of this study were analyzed qualitatively and discussed founded on theoretical basis. Then, it is proposed that the method of describing photographs exposed by Miriam Maninn (2013) can make possible audio description. That way, the right of access and informational inclusion to visually impaired people is guaranteed.

\section{Keywords}

Accessibility. Visually Impaired People. Photographic Description. Photographs Audio Description. Informational Inclusion.

\section{INTRODUÇÃO}

Os arquivos são considerados espaços de guarda e busca pelo conhecimento registrado independente do suporte físico, desta maneira o acesso às informações e aos registros documentais ocorrem de acordo com o grau de acesso estabelecido por lei e também conforme as necessidades físicas apresentadas por seus usuários. Isso vem ao encontro dos autores Barbosa e Franklin (2016, p. 560), segundo os quais “[...] o dever principal do arquivista não é só gerir as informações, mas também torná-las acessíveis a quem necessita independente de suas limitações".

Para tanto, a Arquivologia tem como objetivo principal contribuir no acesso à informação arquivística, atribuindo aos profissionais o desafio de sanar as dificuldades apresentadas pelos usuários que possuem algum tipo de deficiência física, tendo em vista a acessibilidade e a inclusão social dos mesmos nos arquivos.

A fotografia por ser um documento tangível, possui características próprias com conteúdo de informação, "[...] tais como procedência, assunto, autoria, formato, localização espacial, época, cor, textura". Dentro do contexto de descrição de fotografias, percebe-se um obstáculo em relação ao acesso à informação de usuários com deficiência visual, em que acarreta o não acesso dos mesmos por não conseguirem compreender todos os caracteres de informação que compõem a fotografia, fazendo com que alguns traços passem despercebidos pelo usuário com deficiência visual (PATO; MANINI, 2013, p. 2).

No Brasil, 23,9\% da população apresenta algum tipo de deficiência ou necessidade especial, dentre elas visual, auditiva, motora e mental. A deficiência visual corresponde à maior incidência, 18,8\%. Cerca de 35,8 milhões de brasileiros possuem deficiência visual, dos quais mais de 650 mil encontram-se no Amazonas (IBGE, 2010, on-line; SEPED, 2016, online).

Com isso, a acessibilidade e o acesso à informação arquivística são temáticas a serem discutidas por profissionais que atuam em arquivos com a finalidade de sanar as barreiras apresentadas por estas, disponibilizando o acesso à informação e a democratização garantida conforme a legislação vigente (BARBOSA; FRANKLIN, 2016, p. 563).

O método de audiodescrição de fotografias é fundamental para disseminar aos usuários com deficiência visual uma forma padrão de assimilar e acessar a informação de seu interesse. Como fazem notar Nóbrega et al. (2013), no que diz respeito ao objetivo central em transmitir informações visuais, sobre uma descrição objetiva, daquilo que está sendo visualizado para que deficientes visuais tenham acesso a formatos de objetos ou situações visuais a serem transcritas em palavras e traduzidas em sons, apresentados segundo alguns princípios básicos da descrição fotográfica. 
Diante disso, a pesquisa busca compreender o acesso à informação aos documentos fotográficos, utilizando o método de audiodescrição, bem como projetar aos usuários com deficiência visual a acessibilidade e proporcionar a participação e a inclusão social destes aos arquivos.

O objetivo desse estudo foi demonstrar o método de descrição fotográfica para garantir a acessibilidade dos deficientes visuais, assim como de apresentar o documento fotográfico como fonte de informação, elencar estratégias a serem adotadas para o acesso à informação dos deficientes visuais mediante a audiodescrição fotográfica, e, por fim, empregar um método padrão arquivístico para a audiodescrição de fotografias para exposição de um acervo fotográfico.

As fotografias utilizadas são das primeiras contribuições registradas na região amazônica sobre a produção de conteúdo cinematográfico que se deram das experiências do fotógrafo e cineasta Silvino Santos, onde realizou amplo acervo cinematográfico sobre a região amazônica, composto de documentários de média e curta metragem, como também de fotografias em vários formatos de suporte como positivos e negativos em vidro, acetato e papel. Atualmente o acervo do cineasta encontra-se custodiado no Museu da Imagem e do Som do Amazonas (MISAM) (COSTA; LOBO, 2005).

Portanto, este artigo elucida a contribuição da audiodescrição mediante a descrição de documentos fotográficos, apresentando um panorama das dificuldades de acessibilidade para deficientes visuais.

\section{ACESSIBILIDADE E DEFICIÊNCIA VISUAL}

\subsection{Conceitos nos parâmetros da lei}

A legislação brasileira é bem ampla nas questões que envolvem a acessibilidade em defesa dos direitos resguardados pelos cidadãos. Para Sassaki (2011, on-line), a acessibilidade designa o acesso dos indivíduos com deficiência aos serviços de reabilitação física e profissional. O Decreto Federal no 5.296, de 2 de dezembro de 2004, estabelece as condições de acessibilidade no que se aplica aos serviços e utilização de espaços, equipamentos, mobiliários, transportes, meios de comunicação e informação (BRASIL, 2004, on-line).

O mesmo Decreto regulamenta a Lei $\mathrm{n}$ - 10.098, de 19 de dezembro de 2000, conhecida como a "Lei de Acessibilidade", que estabelece normas gerais e critérios básicos para a promoção da acessibilidade das pessoas portadoras de deficiência física ou mobilidade reduzida, consolidada por meio da Lei no 13.146, de 6 de julho de 2015 (BRASIL, 2000, 2015, online).

Porém, existem vários conceitos de acessibilidade que precisam ser considerados, por isso, Sassaki (2011) mostra que existem basicamente seis tipos de abstração que define acessibilidade.

i. Acessibilidade arquitetônica: sem barreiras ambientais físicas, nas residências, nos edifícios, nos espaços urbanos, nos equipamentos urbanos, nos meios de transporte individual ou coletivo.

ii. Acessibilidade comunicacional: sem barreiras na comunicação interpessoal (face-a-face, língua de sinais), escrita (jornal, revista, livro, carta, apostila etc., incluindo textos em braile, uso do computador portátil), virtual (acessibilidade digital).

iii. Acessibilidade metodológica: sem barreiras nos métodos e técnicas de estudo (escolar), de trabalho (profissional), de ação comunitária (social, cultural, artística etc.), de educação dos filhos (familiar). 


\begin{abstract}
iv. Acessibilidade instrumental: sem barreiras nos instrumentos, utensílios e ferramentas de estudo (escolar), de trabalho (profissional), de lazer e recreação (comunitária, turística, esportiva etc.).

v. Acessibilidade programática: sem barreiras invisíveis embutidas em políticas públicas (leis, decretos, portarias etc.), normas e regulamentos (institucionais, empresariais etc.).

vi. Acessibilidade atitudinal: sem preconceitos, estigmas, estereótipos e discriminações, nas pessoas em geral. (SASSAKI, 2011, on-line).
\end{abstract}

Desse modo, a garantia do direito de acesso à informação contribui para democratização e inclusão social da informação, quando o acesso é facilitado a todo e qualquer tipo de usuário independentemente de suas limitações físicas.

Com isso, destacamos a importância da Arquivologia mediante a Lei $n^{\circ} 12.527$, de 18 de novembro de 2011, conhecida como Lei de Acesso à Informação (LAI). Essa lei dispõe que é dever dos órgãos e entidades públicas promover medidas cabíveis que possam garantir o acesso das informações a todo e qualquer cidadão, conforme elucidado nos parâmetros da "Lei da Acessibilidade" e do Artigo 9ํำ da Convenção sobre os Direitos das Pessoas com Deficiência, de 9 de julho de 2008 (BRASIL, 2011, on-line).

Essa garantia do direito de acesso à informação é discutida pelos autores Oliveira, Alves e Maia (2013), que ressaltam a necessidade e perfil de cada usuário na busca pelos serviços de informação ao referirem-se às adaptações para atender aos vários tipos de usuários, pois a informação é direito de qualquer cidadão, independente da cor, raça e status social.

\title{
2.2. Documento fotográfico como fonte de informação e memória
}

Documento pode ser considerado como toda e qualquer informação registrada independente do suporte físico, dotado de conteúdos informacionais que possuem representatividade de resguardar os dados do contexto para qual foi produzido, sendo, portanto, qualquer elemento que o homem pode se expressar. A fotografia é um documento, pois apresenta peculiaridades de registrar determinado fato, o qual se torna artefato fundamental para o conhecimento humano a fim de elucidar os registros, ou seja, as atividades sociais, culturais e revelar um tempo vivido e marcado, pelos quais levaram a sua produção/captura de determinada situação ou contexto histórico (OTLET, 1934 apud BELLOTTO, 2006; RONDINELLI, 2013).

A despeito disso, torna-se oportuno ressaltar as contribuições de Boris Kossoy (2009), o qual afirma que a fotografia é um documento de natureza histórico na condição de seu valor social e cultural. É pelo simples ato fotográfico capturado do tempo e espaço que a informação presente na fotografia evidencia determinada situação histórica.

Ainda sobre essas características do documento fotográfico como documento de arquivo, Miriam Manini (2008) considera que as principais finalidades atribuídas à fotografia pelas instituições/organizações são: comercial; exposição ou publicação; probatório; didático/científico e pessoal/familiar.

\subsection{Métodos de descrição de documentos fotográficos}

A descrição em sua definição abrangente denomina-se como ato de representar ou detalhar determinada situação, objeto, imagem, som, fotografia, documento e etc. como também transcrever em conformidade a representação do original. A descrição de documentos de arquivo serve como ferramenta para elaboração dos instrumentos de pesquisas 
para dar o acesso à informação, onde o profissional de arquivo deve estar ciente das normas e padrões que cada instituição deve associar, tomando como base as normas já existentes (OLIVEIRA, 2012).

As normas para a descrição de documentos arquivísticos surgem das necessidades de padronizar os procedimentos dos arquivos permanentes, com função de propiciar ao arquivista uma série de níveis e características peculiares no processo de descrição, em razão de estabelecer a difusão dos documentos. De acordo com as publicações disponíveis no site do CONARQ, as normas de descrição arquivísticas se caracterizam em cinco categorias, sendo quatro nos padrões aplicados pelas diretrizes internacionais (ISAD (G); ISAAR (CPF); ISDF e ISDIAH) e uma de âmbito nacional (NOBRADE), a qual é adaptada nos parâmetros préestabelecidos pela norma internacional de descrição arquivística - ISAD (G). Desse modo, cada norma possui um critério estabelecido para o nível de descrição de acordo com a necessidade da instituição ou órgão produtor dos documentos a serem descritos (CONARQ, online).

Para melhor compreender os campos descritivos, Manini (2008) adota, em seu modelo de análise, a classe do conteúdo informacional, onde se encontram os dados específicos, sendo este genérico (informação superficial sobre o que se observa) e específico (aquele que demonstra características concretas sobre o objeto enfocado). Essa classe dos dados específicos é dividida nas seguintes categorias:

- Quem/o que - analisa-se a identificação geral daquilo que mostrar a fotografia;

- Onde - deve-se analisar o local do qual foi retirado/capturado o registro fotográfico, observa-se também os principais elementos que ilustram o espaço geográfico apresentado na fotografia;

- Quando - refere-se à cronologia ou ao momento da criação da fotografia;

- Como - consiste em uma descrição mais detalhada referente ao objeto enfocado, levando em consideração os mínimos detalhes que se passam na cena registrada.

Ainda sobre o conteúdo informacional da fotografia, o campo descritivo Sobre apresenta a descrição do assunto geral do que se trata o documento fotográfico, neste caso o que é expresso pela imagem/fotografia e o significado que ela passa. Já o campo da Dimensão Expressiva é representado pelas palavras-chave, pois essas palavras estão relacionadas aos preceitos de facilitar na busca pela informação e assimilação do que a fotografia mostra.

\subsection{Acessibilidade para deficientes visuais: a descrição fotográfica mediante o uso da au- diodescrição}

A audiodescrição traz benefícios aos usuários com necessidades especiais, pois garante o acesso às informações e serve para qualquer usuário independentemente de suas limitações físicas, onde as pessoas com deficiência visual são as mais beneficiadas com esse método. A audiodescrição também é denominada e conhecida pela sigla AD.

De acordo com Franco e Silva (2010, p. 23), a audiodescrição consiste na transformação do conteúdo visual em palavras-chave, para que assim possam ser transmitidas em sons, de forma que estas não passem despercebidas por pessoas com baixa visão ou cegas. Portanto, garante a inclusão informacional e promove a acessibilidade nos arquivos ofertando o direito de acesso à informação. 
Conforme Sant'Anna (2010), a audiodescrição é uma ferramenta utilizável em qualquer situação e de acordo com a realidade apresentada pela instituição, em que oferece dados de informações de acordo com o perfil dos usuários no que apresentam condições de acesso especial. Além disso, a audiodescrição pode ser aplicada nos diversos campos de áreas do conhecimento. Deste modo, a audiodescrição de fotografias propõe cumprir o papel fundamental da difusão e inclusão social (PENA; FERREIRA, 2011).

O processo de audiodescrição pode ser aplicado em qualquer circunstância, seja ela educativa, cultura ou social e deve-se entender que ela é um método que possibilita melhorias a pessoas cegas ou com baixa visão no acesso do conteúdo informacional, neste caso da imagem/fotografia (MICHELON, 2013).

Além de a audiodescrição ser uma ferramenta essencial no processo de transmissão da informação/conteúdo a deficientes visuais, ela se faz da compreensão e descrição da obra original, tendo no áudio/narração elementos necessários que possam servir para transmitir os dados de forma eficiente com a relevância de gerar conhecimento intelectual desses dados e informações audiodescritas.

Nessa percepção dos elementos que compõem o processo de análise da audiodescrição, a autora Christophe (2014) ressalta os principais metadados que devem ser preenchidos e analisados pelo audiodescritor ao realizar a audiodescrição de fotografias. Os princípios elementares da audiodescrição se realizam dos próprios padrões e parâmetros estabelecidos por cada país de acordo com as preferências básicas para descrever, precisamente deve-se fazer uso de um roteiro como base. A primeira orientação é a de descrever o que se observa, ou seja, não resumir, seguido de não interpretar o que se vê ou dar opiniões pessoais e por fim não antecipar informações ou dar informações extras. A autora enfatiza que essas concepções mencionadas acima são referentes a obras publicadas no âmbito internacional, apesar de que no Brasil ainda não existem manuais mais abrangentes nos assuntos que envolvem a audiodescrição de fotografias (CHRISTOPHE, 2014).

Em síntese, os critérios de observação feita pela autora resumem-se em uma série de elementos a serem observados na transcrição da audiodescrição de fotografias, na forma de analisar os princípios básicos e fundamentais da audiodescrição, fazendo-se notório o modelo do Quadro 1.

Quadro 1 - Elementos de observação para audiodescrição de fotografias

\begin{tabular}{|l|}
\hline Parâmetros Elementares da AD \\
\hline Não resumir \\
\hline Não interpretar ou dar opiniões pessoais \\
\hline Descrever o que se vê \\
\hline Atenção aos elementos da composição fotográfica (Luz e Sombra, Linha, Figura, Volume, Textura e Espaço) \\
\hline Princípios Básicos para a AD de Fotografias \\
\hline Informações sobre dimensões e disposição da fotografia \\
\hline Descrição partindo do mais geral para o mais específico \\
\hline Informações sobre cor, textura e sombreamento \\
\hline Informações sobre perspectiva, foco e plano \\
\hline Localização dos itens a partir do ponto de vista do espectador \\
\hline Priorização de itens em destaque \\
\hline Não havendo destaques, descrever partindo da direita para a esquerda, de cima para baixo \\
\hline Uso de comparações sinestésicas \\
\hline Evita o uso de referências visuais \\
\hline Uso de linguagem clara e objetiva \\
\hline Uso de figuras de linguagem \\
Fonte: Christophe (2014).
\end{tabular}


A audiodescrição vem conquistando diversos campos do conhecimento, trazendo o benefício de descrever e gerar acessibilidade aos deficientes visuais, na medida em que traduz em palavras aquilo que os olhos das pessoas cegas ou com baixa visão não podem enxergar. Nesse contexto, permite que um dos sentidos do corpo humano, no caso a audição, possa ser o canal para transmitir e compreender a informação presente no documento fotográfico.

\section{METODOLOGIA}

Os procedimentos metodológicos utilizados neste estudo caracterizam-se como de natureza aplicada, tendo como objetivo gerar conhecimentos para aplicação prática. Quanto à abordagem da pesquisa, é classificada como qualitativa, pois busca identificar e conhecer os métodos de descrição fotográficos aplicados com base no conhecimento arquivístico, visando abordar os métodos de descrição de documentos fotográficos à luz da audiodescrição como fonte de acessibilidade a deficientes visuais. Quanto aos procedimentos técnicos, a pesquisa caracteriza-se como bibliográfica e documental. Para o levantamento dos resultados, levou-se em considerações a técnica de análise fotográfica abordada por Miriam Manini (2008), na qual permite apresentar as abordagens do ponto de vista qualitativo na observação direta das informações visualizadas no documento fotográfico, mediante a descrição dos dados pela aplicação da audiodescrição.

Foram adotados três procedimentos técnicos:

1) Construção do referencial teórico por meio do método da pesquisa bibliográfica;

2) Análise dos dados e do conteúdo informacional das fotografias do acervo fotográfico do cineasta Silvino Santos, com base no quadro elaborado pela autora Miriam Manini (2008) e adaptado para o estudo;

3) Descrição através do método documental e ampliação dos detalhes das expressões fotográficas, utilizando recursos de mídias tecnológicas como gravador de áudio e o software Movie Maker para edição e gravação sonora e audiovisual, em vista que a pesquisa visa abordar pessoas com baixa visão e cegas.

Para este estudo foi necessário acrescentar ao quadro adaptado pela autora Miriam Manini mais dois novos campos descritivos, o primeiro consiste na descrição de uma síntese de todos os dados obtidos pela análise do conteúdo informacional e da dimensão expressiva e o segundo faz uso da apropriação da síntese para realizar a tradução da audiodescrição, a qual serviu como roteiro para narração, conforme Quadro 2.

Quadro 2 - Modelo de análise fotográfica para audiodescrição

\begin{tabular}{|c|c|c|c|c|}
\hline \multirow{3}{*}{ Categoria } & \multicolumn{3}{|c|}{ Conteúdo informacional } & \multirow{3}{*}{$\begin{array}{l}\text { Dimensão } \\
\text { expressiva }\end{array}$} \\
\hline & \multicolumn{2}{|c|}{$\mathrm{DE}$} & \multirow{2}{*}{ Sobre } & \\
\hline & Genérico & Especifico & & \\
\hline \multicolumn{5}{|l|}{ Quem/o que } \\
\hline \multicolumn{5}{|l|}{ Onde } \\
\hline \multicolumn{5}{|l|}{ Quando } \\
\hline \multicolumn{5}{|l|}{ Como } \\
\hline \multicolumn{5}{|l|}{ Síntese } \\
\hline Tradução da AD & & & & \\
\hline
\end{tabular}

Fonte: Adaptado de Manini (2008, p. 169). 
Foram utilizadas cinco fotografias do acervo do cineasta Silvino Santos, documentos estes custodiados pelo MISAM, os quais servem como documentos para uso de exposição aos usuários que frequentam o local, onde foi escolhido uma fotografia de cada uma das seguintes categorias: fauna, enchente, extrativismo, objetos e indígenas. Após a seleção dessas fotografias realizou-se a descrição fotográfica adaptado de Manini, assim como a audiodescrição, adotando os critérios abordados pela autora Christophe (2014) no que se refere aos elementos básicos e princípios da AD.

Após a análise do conteúdo informacional e a dimensão expressiva no documento fotográfico, foi elaborado a audiodescrição com apoio das informações descritas no Quadro 2, levando em consideração os princípios elementares e básicos da fotografia.

Foi escolhido este método devido à praticidade de ser manuseado por qualquer profissional que desenvolva descrição de acervos fotográficos, pois essa metodologia se diferencia de demais normas e métodos pela facilidade de agregar/preencher as informações observadas. Levaram-se em consideração as limitações dos deficientes visuais em busca de um método padrão para audiodescrever fotografias, pois a audiodescrição deve ser simples, de fácil entendimento e não pode ser algo exaustivo para o usuário. Neste posicionamento, as normas de descrição arquivísticas existentes que poderiam ser utilizadas, como da Norma Brasileira de Descrição Arquivística (NOBRADE) e o modelo de catalogação para coleções fotográficas (SEPIADES) não seriam viáveis pela quantidade de campos e níveis estruturais que estas permitem alcançar.

\section{RESULTADOS DA PESQUISA}

O documento fotográfico representa mais do que informação, ele apresenta o contexto da conotação de um espaço, tempo, pessoas, seres e objetos, pois a percepção fotográfica pode representar diversas convergências em torno de quem a observa e a interpreta, o qual cria certa percepção sobre objeto enfocado por meio dos elementos expressivos que contém a fotografia. Por outro lado, ela pode inibir alguns detalhes que envolvem a cena registrada, trata-se da captura de apenas determinada dimensão de espaço, levando-nos a crer naquilo que está sendo visualizado. A audiodescrição tem como papel fundamental assegurar o direito resguardado pelos deficientes visuais na necessidade de promover acessibilidade informacional a estes, mediante os dispositivos estabelecidos por lei, a fim de difundir aos usuários o acesso à informação independente de suas limitações.

Para este estudo, foram analisadas cinco fotografias do acervo fotográfico de Silvino Santos, dentre elas é exemplificado, conforme o Apêndice $A$, a fotografia que representa $o$ extrativismo na Amazônia. A escolha deste registro fotográfico deu-se mediante a intenção de demonstrar as raízes caboclas deixadas pelos nossos antepassados, pelos homens que vivenciaram o auge do ciclo da borracha na Região Amazônica, tendo como característica o látex que foi o forte da economia durante muitos anos, o qual atraiu para o Amazonas olhares do comércio exterior que pôde explorar do látex das seringueiras às riquezas de nossa região. Com isso, a borracha passou a ser um produto de alto valor e investimento para as atividades desenvolvidas por grandes indústrias, especificamente a indústria automobilística. Entretanto, o látex das seringueiras amazônicas era comercializado em países da Europa e Estados Unidos. Já nos dias de hoje, a economia do Amazonas se potencializa nas fábricas do polo industrial de Manaus, assim como se baseia no extrativismo de produtos como madeira, gasoduto, guaraná, castanha, açaí e muitos outros recursos disponíveis aqui na Região Norte (COSTA, 2012). 
Após o término da descrição fotográfica de acordo com os parâmetros préestabelecidos nos procedimentos metodológicos, o próximo passo consistiu na realização/elaboração de uma tecnologia assistiva, neste caso à audiodescrição de fotografias. Com ajuda de ferramentas disponíveis na internet para downloads gratuitos, foi utilizado o software Movie Maker para edição das fotografias, juntamente com a gravação e narração com base no roteiro da tradução da audiodescrição feita na análise dos resultados deste trabaIho. Foi gravado um DVD, com a finalidade de ser usado em uma determinada exposição de documentos fotográficos pelo próprio museu.

\section{CONSIDERAÇÕES FINAIS}

O desenvolvimento desta pesquisa deu-se mediante a necessidade de oferecer aos usuários portadores de deficiência visual o acesso e a inclusão do conteúdo informacional presente nos documentos de arquivo. Assim como, abordou a descrição do documento fotográfico como objeto de estudo, no qual evidenciou a relevância de oferecer e gerar acessibilidade informacional a estes por meio da audiodescrição de fotografias. Diante da realidade apresentada, os objetivos deste trabalho compreenderam-se em apresentar o documento fotográfico como fonte de informação, assim como propôs em adotar uma estratégia na promoção de assegurar aos deficientes visuais o acesso e a difusão da informação arquivística. O último objetivo buscou empregar um método padrão arquivístico para descrever fotografias à luz da audiodescrição.

Dada a importância do tema, torna-se necessário futuramente a exposição da audiodescrição dessas fotografias pelo próprio MISAM, com objetivo de demonstrar a contribuição do arquivista no processo de ferramentas que viabilizem no acesso e na inclusão de seus usuários. Nesse sentido, cabe ressaltar a importância da continuidade desse estudo, para que este seja ampliado e revisado em decorrências das demais necessidades e limitações existentes, com o intuito de gerar novos resultados e colocar o profissional arquivista frente os desafios da acessibilidade informacional com a garantia de tornar os arquivos mais inclusos na sociedade, ou seja, oferecer serviços em prol de pessoas com necessidades especiais, fazendo com que estes procurem pelas informações contidas nos Arquivos.

\section{REFERÊNCIAS}

AMAZONAS. Secretaria de Estado dos Direitos da Pessoa com Deficiência - SEPED. 2016. Disponível em: http://www.seped.am.gov.br/pagina/leis-da-pessoa-com-deficiencia/. Acesso em: 02 abr. 2017.

BARBOSA, I. R.; FRANKLIN, K. P. S. A função social do arquivista: uma abordagem sobre inclusão e acessibilidade nos arquivos. In: Congresso Nacional de Arquivologia - CNA, 7., 2016, Fortaleza. Anais eletrônicos... Revista Analisando em Ciência da Informação - RACIn, João Pessoa, v. 4, n. especial, p. 559-568, out. 2016. Disponível em: http://racin.arquivologiauepb.com.br/edicoes/v4 nesp/racin v4 nesp artigo 05590568.pdf. Acesso em: 02 abr. 2017.

BELLOTTO, H. L. Arquivos permanentes: tratamento documental. 4. ed. reimpr. Rio de Janeiro: FGV, 2006. 
BORIS, K. Fotografia \& História. 3. ed. rev. São Paulo: Ateliê Editorial, 2009.

BRASIL. Presidência da República. Decreto no 5.296, de 2 de dezembro de 2004. Regulamenta as Leis nos 10.048 , de 8 de novembro de 2000 , que dá prioridade de atendimento às pessoas que especifica, e 10.098, de 19 de dezembro de 2000, que estabelece normas gerais e critérios básicos para a promoção da acessibilidade das pessoas portadoras de deficiência ou com mobilidade reduzida, e dá outras providências. Disponível em:

http://www.planalto.gov.br/ccivil 03/ ato2004-2006/2004/decreto/d5296.htm. Acesso em: 02 abr. 2017.

BRASIL. Presidência da República. Lei no 10.098, de 19 de dezembro de 2000. Estabelece normas gerais e critérios básicos para a promoção da acessibilidade das pessoas portadoras de deficiência ou com mobilidade reduzida, e dá outras providências. Brasília, 2000. Disponível em: http://www.planalto.gov.br/ccivil 03/leis/l10098.htm. Acesso em: 02 abr. 2017.

BRASIL. Presidência da República. Lei no 12.527, de 18 de novembro de 2011. Regula o acesso a informações previsto no inciso XXXIII do art. $5^{\circ}$, no inciso II do $\S 3^{\circ}$ do art. 37 e no $\S 2^{\circ}$ do art. 216 da Constituição Federal; altera a Lei $n^{\circ}$ 8.112, de 11 de dezembro de 1990; revoga a Lei $n^{\circ} 11.111$, de 5 de maio de 2005, e dispositivos da Lei $n^{\circ} 8.159$, de 8 de janeiro de 1991; e dá outras providências. Disponível em: http://www.planalto.gov.br/ccivil 03/ ato20112014/2011/lei/l12527.htm. Acesso em: 04 abr. 2017.

BRASIL. Presidência da República. Lei $n^{\circ}$ 13.146, de 6 de julho de 2015. Institui a Lei Brasileira de Inclusão da Pessoa com Deficiência (Estatuto da Pessoa com Deficiência). Brasília, 2015. Disponível em: http://www.planalto.gov.br/ccivil 03/ ato20152018/2015/lei/l13146.htm. Acesso em: 18 jun. 2017.

CHRISTOPHE, M. C. Traduzindo olhares: a influência da formação do audiodescritor na audiodescrição de fotografias. 2014. 69 f. Trabalho de Conclusão de Curso (Graduação em Letras) - Universidade Federal da Bahia, Salvador, 2014. Disponível em: http://repositorio.ufba.br/ri/handle/ri/17151. Acesso em: 08 abr. 2017.

CONSELHO NACIONAL DE ARQUIVOS (CONARQ). Normas de descrição arquivística. Rido de Janeiro: Arquivo Nacional, 2006. Disponível em:

http://conarq.arquivonacional.gov.br/images/publicacoes textos/nobrade.pdf. Acesso em 29 maio 2017.

COSTA, F. A. Formação rural extrativista na Amazônia: os desafios do desenvolvimento capitalista (1720-1970). Belém: NAEA, 2012. (Coleção Economia Política da Amazônia. Série III Formação histórica, v. 1).

COSTA, S. V.; LOBO, N. J. F. Cinema no Amazonas. Estudos Avançados, São Paulo, v. 19, n. 53, p. 295-298, abril de 2005. Disponível em http://www.scielo.br/scielo.php?script=sci arttext\&pid=S010340142005000100018\&lng=pt\&nrm=iso. Acesso em: 24 jul. 2017. 
COTOMACCI, G. Lazer: direitos e acessibilidade das pessoas com deficiência ou necessidades especiais. 2007. 84 f. Trabalho de Conclusão de Curso (Graduação em Educação Física) - Faculdade de Educação Física, Universidade Estadual de Campinas, Campinas, 2007. Disponível em: http://www.bibliotecadigital.unicamp.br/document/?code=000437308. Acesso em: 02 abr. 2017.

FRANCO, E. P. C.; SILVA, M. C. C. Audiodescrição: Breve Passeio Histórico. In: MOTTA, L. M. V.; ROMEU FILHO, P. (Orgs.). Audiodescrição: transformando imagens em palavras. São Paulo: Secretaria dos Direitos da Pessoa com Deficiência do Estado de São Paulo, 2010.

INSTITUTO BRASILEIRO DE GEOGRAFIA E ESTATísTICA (IBGE). Censo Demográfico 2010. Disponível em:

http://www.ibge.gov.br/home/presidencia/noticias/imprensa/ppts/0000000847310412201 2315727483985.pdf. Acesso em: 02 abr. 2017.

MANINI, M. P. A fotografia como registro e como documento de arquivo. In: BARTALO, L.; MORENO, N. A. (Org.). Gestão em Arquivologia: abordagens múltiplas. Londrina: EDUEL, 2008 , v. 1, p. $119-183$.

MICHELON, F. F. Palavras que levam a imagens: fotografia para ouvir. Discursos fotográficos, Londrina, v. 9, n. 15, p. 189-210, jul./dez. 2013. Disponível em:

http://www.uel.br/revistas/uel/index.php/discursosfotograficos/article/view/13118. Acesso em: 08 abr. 2017.

NÓBREGA, A. et al. (Org.) Notas proêmias - acessibilidade comunicacional para produções culturais. [S.I.]: Cepe, 2013.

OLIVEIRA, L. M. V. Descrição e pesquisa: reflexões em torno dos arquivos pessoais. Rio de Janeiro: Móbile, 2012.

OLIVEIRA, M. A. D.; ALVES, M. V.; MAIA, M. A. Q. A função social do profissional da informação numa biblioteca inclusiva. Anais do Congresso Brasileiro de Biblioteconomia, Documentação e Ciência da Informação, Florianópolis, v. 5, 2013. Disponível em:

https://www.portal.febab.org.br/anais/article/view/1600/1601. Acesso em: 04 abr. 17.

PATO, P. R. G.; MANINI, M. P. Polissemia da imagem, indexação e recuperação da informação. In: ENCONTRO NACIONAL DE PESQUISA EM CIÊNCIA DA INFORMAÇÃO, 14., 2013, Florianópolis. Anais [...] Florianópolis: ANCIB, 2013. Disponível em:

http://enancib.sites.ufsc.br/index.php/enancib2013/XIVenancib/paper/viewFile/43/409. Acesso em: 05 abr. 2017.

PENA, M. A. L.; FERREIRA, F. F. O direito dos deficientes visuais à audiodescrição. Cadernos de Ciências Sociais Aplicadas, n. 11, p. 51-70, 2011. Disponível em:

http://periodicos.uesb.br/index.php/cadernosdeciencias/article/viewFile/1728/1591. Acesso em: 08 abr. 2017. 
RONDINELLI, R. C. $\mathbf{O}$ documento arquivístico ante a realidade digital: uma revisão conceitual necessária. Rio de Janeiro: FGV, 2013.

SANT'ANNA, L. A importância da audiodescrição na comunicação das pessoas com deficiência. In: MOTTA, L. M. V. M.; ROMEU FILHO, P. (Org.). Audiodescrição: transformando imagens em palavras. São Paulo: Secretaria dos Direitos da Pessoa dom Deficiência do Estado de São Paulo, 2010, p. 151-158. Disponível em:

http://pessoacomdeficiencia.sp.gov.br/usr/share/documents/LIVRO AUDIODESCRICAO TRA NSFORMANDO IMAGENS EM PALAVRAS.pdf. Acesso em: 02 abr. 2017.

SASSAKI, R. K. Conceito de acessibilidade. Rio de Janeiro: Escola de gente, 2011. Disponível em: http://www.escoladegente.org.br/noticiaDestaque.php?id=459. Acessado em: 02 abr. 2017.

SILVA, M. C. C. C.; FRANCO, E. P. C. Audiodescrição: breve passeio histórico. In: MOTTA, L. M. V. M.; ROMEU FILHO, P. (Orgs.). Audiodescrição: transformando imagens em palavras. São Paulo: Secretaria dos Direitos da Pessoa dom Deficiência do Estado de São Paulo, 2010, p. 23-42. Disponível em:

http://pessoacomdeficiencia.sp.gov.br/usr/share/documents/LIVRO AUDIODESCRICAO TRA NSFORMANDO IMAGENS EM PALAVRAS.pdf. Acesso em: 02 abr. 2017. 


\section{APÊNDICE A - AUDIODESCRIÇÃO 01- CATEGORIA: EXTRATIVISMO}

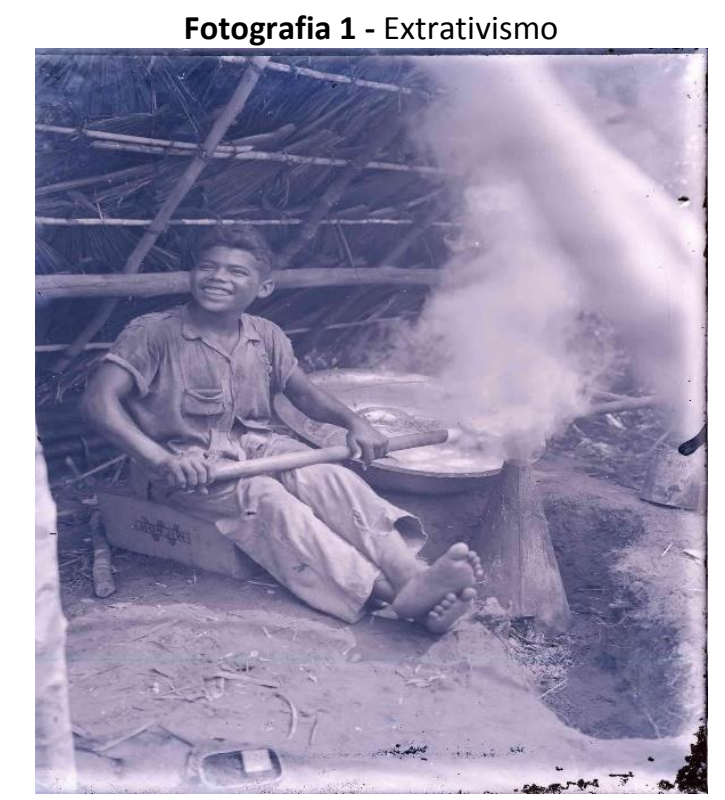

Foto: Silvino Santos. Acervo do Museu da Imagem e do Som do Amazonas.

\begin{tabular}{|c|c|c|c|c|}
\hline \multirow{3}{*}{ Categoria } & \multicolumn{3}{|c|}{ Conteúdo informacional } & \multirow{3}{*}{ Dimensão expressiva } \\
\hline & \multicolumn{2}{|c|}{ DE } & \multirow{2}{*}{ Sobre } & \\
\hline & Genérico & Específico & & \\
\hline Quem/o que & $\begin{array}{l}\text { - Bacia de alumí- } \\
\text { nio } \\
\text { - Caixa de madei- } \\
\text { ra }\end{array}$ & $\begin{array}{l}\text { - Casa de defuma- } \\
\text { ção } \\
\text { - Homem jovem } \\
\text { - Seringueiro } \\
\text { - Defumação de } \\
\text { látex } \\
\text {-Vulcanização } \\
\text { - Fumaça } \\
\text { - Preparação das } \\
\text { bobinas de látex }\end{array}$ & \multirow[t]{4}{*}{ Extrativismo } & \multirow[t]{4}{*}{$\begin{array}{l}\text { - Jovem seringueiro } \\
\text { sorrindo } \\
\text { - Close preparação das } \\
\text { bobinas de látex } \\
\text { - Descalço } \\
\text { - Fumaça branca }\end{array}$} \\
\hline Onde & $\begin{array}{l}\text { Casa de } \\
\text { vulcanização }\end{array}$ & & & \\
\hline \multicolumn{3}{|l|}{ Quando } & & \\
\hline Como & & $\begin{array}{l}\text { Jovem trajando } \\
\text { roupas sujas e des- } \\
\text { gastadas }\end{array}$ & & \\
\hline Síntese & \multicolumn{4}{|c|}{$\begin{array}{l}\text { A fotografia representa uma das atividades desempenhadas por um seringueiro no } \\
\text { período auge da borracha a mesma se passa em um defumador de látex. }\end{array}$} \\
\hline $\begin{array}{l}\text { Tradução da } \\
\text { Audiodescrição }\end{array}$ & \multicolumn{4}{|c|}{$\begin{array}{l}\text { A fotografia ilustrada é na cor preto e branco, em seu plano geral observa-se um serin- } \\
\text { gueiro jovem moreno, descalço, sentado em cima de uma caixa de madeira, o qual usa } \\
\text { roupas sujas e desgastadas pela ação do tempo, o mesmo desempenha a atividade de } \\
\text { defumação que é a mistura do látex com enxofre que consiste em transformá-las em } \\
\text { bolas de borrachas, esse processo ocorre devido a vulcanização, pois esta atividade se } \\
\text { dá mediante a queima do látex com o uso de em fogão feito de argila/barro em forma- } \\
\text { to triangular. Na fotografia temos como objeto enfocado a expressão facial do sorriso } \\
\text { do seringueiro ao entorno da fumaça branca que sai do vulcanizador. }\end{array}$} \\
\hline
\end{tabular}

